\title{
Assessment of The Accuracy of The MR Abdominal Adipose Tissue Volumetry using 3D Gradient Dual Echo 2-Point DIXON Technique using CT as Reference
}

\author{
Sung-Jin Kang* \\ Dept. of Radiology, Soonchunhyang University Bucheon Hospital, Republic of Korea
}

(Received 20 October 2016, Received in final form 9 December 2016, Accepted 12 December 2016)

\begin{abstract}
In this study, in order to determine the validity and accuracy of MR imaging of 3D gradient dual echo 2-point DIXON technique for measuring abdominal adipose tissue volume and distribution, the measurements obtained by CT were set as a reference for comparison and their correlations were evaluated. CT and MRI scans were performed on each subject (17 healthy male volunteers who were fully informed about this study) to measure abdominal adipose tissue volume. Two skilled investigators individually observed the images acquired by $C T$ and MRI in an independent environment, and directly separated the total volume using region-based thresholding segmentation method, and based on this, the total adipose tissue volume, subcutaneous adipose tissue volume and visceral adipose tissue volume were respectively measured. The correlation of the adipose tissue volume measurements with respect to the observer was examined using the Spearman test and the interobserver agreement was evaluated using the intra-class correlation test. The correlation of the adipose tissue volume measurements by $C$ T and MRI imaging methods was examined by simple regression analysis. In addition, using the Bland-Altman plot, the degree of agreement between the two imaging methods was evaluated. All of the statistical analysis results showed highly statistically significant correlation $(p<0.05)$ respectively from the results of each adipose tissue volume measurements. In conclusion, MR abdominal adipose volumetry using the technique of 3D gradient dual echo 2-point DIXON showed a very high level of concordance even when compared with the adipose tissue measuring method using CT as reference.
\end{abstract}

Keywords : visceral adipose tissue, subcutaneous adipose tissue, DIXON, MRI

\section{Introduction}

Obesity is a well-known incremental health risk factor, which is closely related to several metabolic disorders such as hypertension, cardiovascular disease, type 2 diabetes, and dyslipidemia [1, 2]. The risk factors associated with the metabolic syndrome have been reported to be more closely related to the accumulation of visceral fat rather than the accumulation of subcutaneous fat [3-6], and therefore, in order to manage and prevent these diseases, accurate and repeated measurement of the quantitative distribution of body fat can be regarded as being very important for clinical and research purposes.

For body fat assessment, a few methods such as anthropometry, bioelectrical impedance analysis (BIA) and dual X-ray absorptiometry (DXA) are being used clinically, but these methods have problems in that they are gene-

CThe Korean Magnetics Society. All rights reserved.

*Corresponding author: Tel: +82-32-621-6566

Fax: +82-32-621-5874, e-mail: xray116@hanmail.net rally inaccurate or that they cannot be used for assessment of visceral fat content [7-10]. Computed tomography (CT) and Magnetic resonance imaging (MRI) are generally recognized as being useful in vivo evaluation methods for directly measuring the body fat distribution [11-14]. In particular, CT is the best way to measure the distribution of adipose tissues quantitatively $[15,16]$. According to the research of Yoon et al., body fat measurement using CT showed a very high measurement accuracy between examiners in a study employing phantoms and volunteers [17]. However, CT is not easy to apply to the examination of children or women of childbearing age due to the necessary exposure to radiation and thus, it has a limitation in being suitable to repeated follow-ups for research targeting healthy subjects.

Previously, several studies have introduced adipose tissue measuring methods by MRI, but in most cases, spin echo T1 weighted, spoiled gradient echo T1 weighted and T1 FLAIR (T1 weighted fluid attenuated inversion recovery) techniques were applied to measure the ratio of anatomical cross-sectional area of the subcutaneous adipose 
tissue and visceral adipose tissue passing through the $4 \sim 5$ th lumbar and the relevant correlations were presented $[18,19]$. However, given that the reference for the crosssection can vary depending on the body type, age and sex of the subjects [20-22], the method measuring the distribution ratio of fat area using a specific cross-section is difficult to be universally applied for clinical assessment of various metabolic disorders.

Recently, uniform fat suppression imaging and fat quantification methods using DIXON imaging technique are attracting attention [23-26]. In DIXON imaging, taking advantage of the water-fat phase shifts as generated by the difference in the resonance frequency between fat and water, four kinds of images of "water-only," "fatonly," "in-phase" and "out-of-phase" can be reconstructed from a single image acquisition based on the signals acquired from two different phases. If applied to the three-dimensional imaging acquisition method, a voluminal image with only adipose tissue selectively excited, can be acquired, including sufficiently the abdomen in a relatively short period of time. In this study, in order to determine the validity and accuracy of a method measuring abdominal adipose tissue volume and the amount of its distribution using MR imaging of 3D Gradient dual echo 2-point DIXON technique, the measurements obtained by CT were set as a reference for comparison and their correlations were evaluated.

\section{Subjects and Methods}

\subsection{Study design $\&$ volunteers}

For the selection of subjects, 17 healthy male volunteers who were fully informed about this study and had then agreed to participate were enrolled. The height $(\mathrm{m})$ and body weight $(\mathrm{kg})$ of all subjects were measured, from which the body mass index (BMI) was calculated by dividing the body weight in kilograms by square of height in meters $\left(\mathrm{kg} / \mathrm{m}^{2}\right)$.

CT and MRI scans were performed on each subject to measure abdominal adipose tissue volume. For CT and MRI scans, the subject was in the supine position with both arms raised over the head and a voluminal image including the transverse cross-section that connects the diaphragm up to the anterior superior iliac spine (ASIS) (the average scan range was $44 \mathrm{~cm}$ with range of 40-46 $\mathrm{cm})$ was acquired by one inhalation. All subjects were fasted more than 6 hours before the scanning and MRI scanning was sequentially followed by CT scanning within a few minutes to minimize the measurement errors which can be caused by food in the gastrointestinal tract and displacement of the abdominal organs due to time lapse.

\subsection{CT \& MR imaging techniques}

For acquisition of CT images, a multi-detector CT scanner (Discovery CT 750HD, GE Healthcare, Milwaukee, WI, USA) equipment was used, in which the following imaging parameters were applied: tube voltage of 120 $\mathrm{kVp}$, tube current of 120-350 mA (smart mA, noise index: 17), standard reconstruction algorithm, $40 \mathrm{~mm}$ detector coverage, pitch of $39.37 \mathrm{~mm} /$ rotation, $0.625 \mathrm{~mm}$ helical thickness, rotation time of $0.6 \mathrm{sec}$, matrix size of $512 \times$ 512 , and display field of view being $44 \mathrm{~cm}$. Based on the acquired source images (raw data), $5 \mathrm{~mm}$ thick transverseaxial plane images were reconstructed, which were used for the measurement.

For acquisition of MR images, a 3.0T MR scanner (Signa 3.0T HDxt. GE Healthcare, Waukesha, WI, USA) and an 8-channel torso array (GE Healthcare, Aurora, OH, USA) receiving coils were used and using $3 \mathrm{D}$ gradient dual echo 2-point DIXON (GE termed 3D LAVA-flex) technique following imaging parameters was applied with the following parameters: TR: $5.8 \mathrm{~ms}$, TE1: $1.3 \mathrm{~ms}$, TE2: 2.6 ms, flip angle: $12^{\circ}$, bandwidth: $142.86 \mathrm{kHz}$, slice thickness/ spacing: 10/0 $\mathrm{mm}$ (zero-filled interpolation reconstruction slice: $5 \mathrm{~mm}$ ), matrix size: $256 \times 256$ (zero-filled interpolation reconstruction matrix: $512 \times 512$ ), averaging: 1 , field of view: $44 \mathrm{~cm}$, parallel imaging (GE termed ARC) acceleration factor of 2.0, and scan time: $25-32 \mathrm{sec}$. In addition, the changes in the brightness of the signal intensity due to the sensitivity distribution of the receiving coil were corrected (surface coil intensity correction), and the signal reduction caused by T2* effects was not considered when using the 2-point DIXON technique.

\subsection{Adipose tissue volumetry}

For measurement of the adipose tissue volume, AW VolumeShare 5 program (Advantage Workstation Rel 4.6, GE Healthcare) was used.

For classification of the adipose tissue, by setting the muscles surrounding the abdominal cavity and the peritoneum as borders, the inside and outside were divided into visceral adipose tissue and subcutaneous adipose tissue, respectively (Fig. 1).

Two skilled investigators individually observed the images acquired by $\mathrm{CT}$ and MRI in an independent environment, and directly separated the total volume using region based thresholding segmentation method $[15,17,27]$, and based on this, the total adipose tissue volume (TATV) and visceral adipose tissue volume (VATV) were measured respectively. In addition, by subtracting these values, the subcutaneous adipose tissue volume 


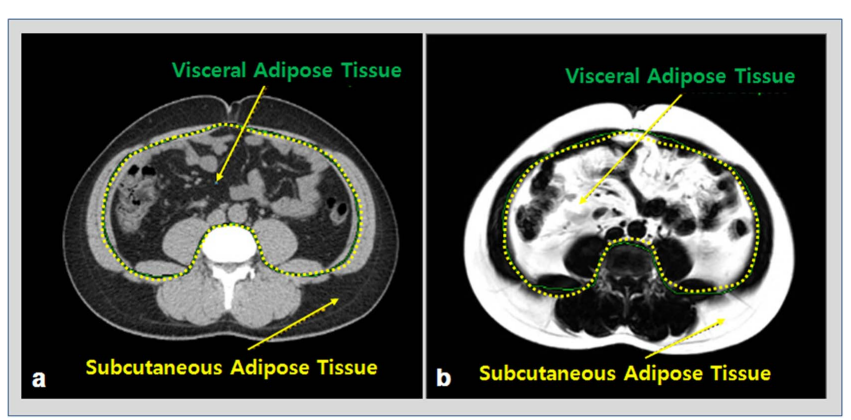

Fig. 1. (Color online) The subcutaneous adipose tissue and visceral adipose tissue separation line (dotted) on trans verseaxial images at the navel level by computed tomography image (a) and magnetic resonance imaging (b), respectively, acquisitions in the same subject. The region inside the separation line is the visceral adipose tissue and the region outside the separation line is subcutaneous adipose tissue.
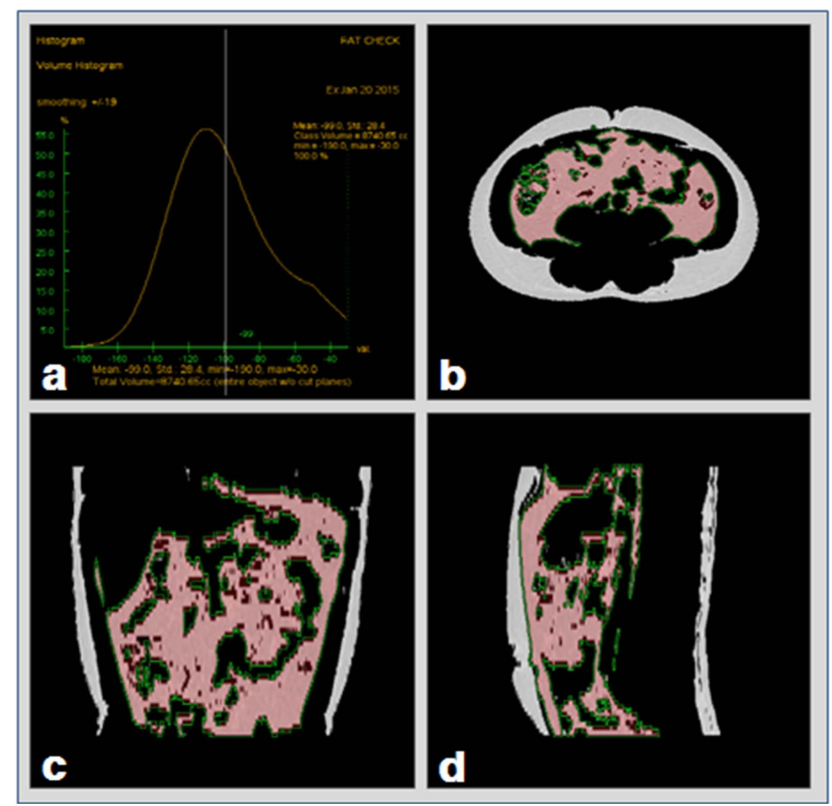

Fig. 2. (Color online) From the computed tomography images, total adipose tissue volume (TATV) and visceral adipose tissue volume (VATV) were measured by region-based thresholding segmentation method using within -190 to -30 Hounsfield Unit (HU) attenuation range. Adipose tissue within bone marrow and paraspinal muscles were excluded from the adipose tissue volume measurement. Histograms of HU attenuation range (a), region-based thresholding segmentation on transverse-axial planes (b), coronal planes (c), and sagittal planes (d). Subcutaneous adipose tissue volume (SATV) was calculated (not directly measured) as the subtraction of measured TATV and measured VATV. We selected the SATV to be the denominator for the computation of visceral adipose tissue ratio (VATV/SATV), which was compared between Observer 1 and Observer 2.
(SATV) was calculated along with the ratio of VATV/ SATV. At this time, the adipose tissues located in the bone marrow and around the paraspinal muscle were excluded from all the measured volume. Cubic centimeters $\left(\mathrm{cm}^{3}\right)$ was used as the unit of adipose tissue volumetry.

For CT images, the adipose tissue within the range of -190 to -30 Hounsfield units (HU) presented in a previous study [15] was selected and the volume of interest (VoI) was set using region-based thresholding segmentation method to measure the volume of the adipose tissue (Fig. 2).

For MR images, the background noise and artifacts were excluded from the "fat-only" images acquired by 3D Gradient dual echo 2-point DIXON imaging technique. To measure the volume of the adipose tissue, the ranges of the signal intensity (SI) (including all subjects, minimum
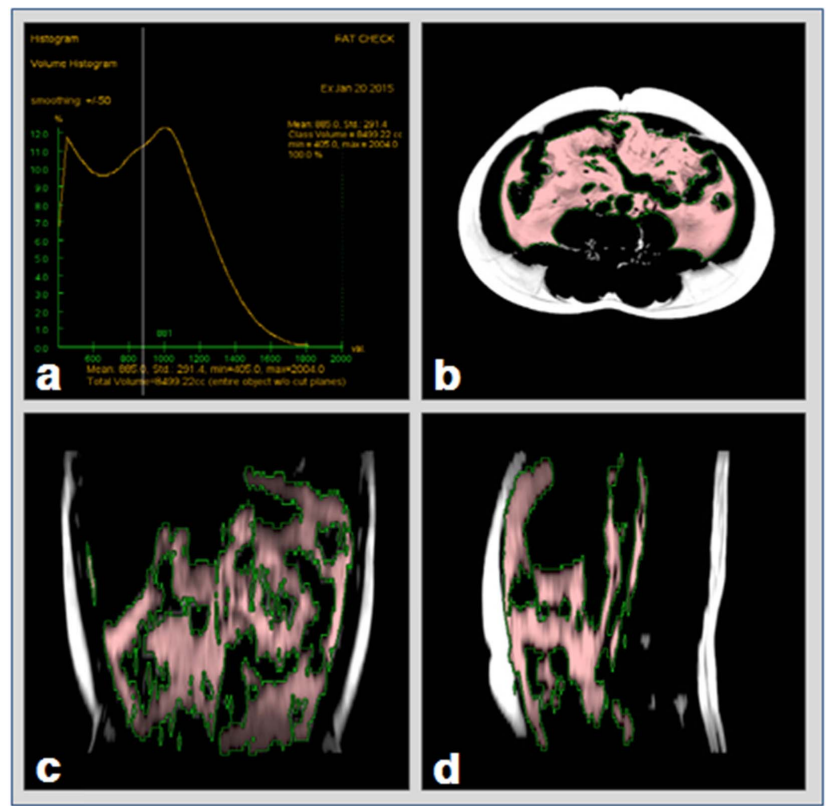

Fig. 3. (Color online) From the magnetic resonance images, total adipose tissue volume (TATV) and visceral adipose tissue volume (VATV) were measured by region-based thresholding segmentation method using signal intensity values (within applied minimum value $313 \sim$ maximum value 2,381 in all subjects). Adipose tissue within bone marrow and paraspinal muscles were excluded from the adipose tissue volume measurement. Histogram of signal intensity values range (a), region-based thresholding segmentation on transverseaxial planes (b), coronal planes (c), and sagittal planes (d). Subcutaneous adipose tissue volume (SATV) was calculated (not directly measured) as the subtraction of measured TATV and measured VATV. We selected the SATV to be the denominator for the computation of visceral adipose tissue ratio (VATV/SATV), which was compared between Observer 1 and Observer 2. 
of $313 \sim$ maximum of 2,381), which fully include the adipose tissue visually recognized, were selected and the volume of interest (VoI) was set using region-based thresholding segmentation method (Fig. 3).

\subsection{Statistical analysis}

For the adipose tissue volume measured for each part, the difference in the measured values by MRI and CT and the ratio of the measured values by MRI to those by CT were calculated. The correlation of the adipose tissue volume measurements by observer was examined using Spearman test. The inter-observer agreement was evaluated using intra-class correlation (ICC) test.

The correlation of the adipose tissue volume measure-

Table 1. Measured volumes of adipose tissues using CT and MRI in 17 subjects by two observers.

\begin{tabular}{|c|c|c|c|c|c|c|c|c|c|c|}
\hline \multirow{2}{*}{\multicolumn{2}{|c|}{$\begin{array}{l}\text { No. of } \\
\text { subjects }\end{array}$}} & \multirow{2}{*}{$\begin{array}{c}\mathrm{BMI} \\
\left(\mathrm{kg} / \mathrm{m}^{2}\right)\end{array}$} & \multicolumn{4}{|c|}{$\begin{array}{l}\text { Adipose tissue volume measured using } \\
\qquad \mathrm{CT}\left(\mathrm{cm}^{3}\right)\end{array}$} & \multicolumn{4}{|c|}{$\begin{array}{l}\text { Adipose tissue volume measured using } \\
\qquad \text { MRI }\left(\mathrm{cm}^{3}\right)\end{array}$} \\
\hline & & & TATV & VATV & SATV & VATV /SATV & TATV & VATV & SATV & VATV /SATV \\
\hline \multirow{17}{*}{$\begin{array}{c}\text { Observer } \\
1\end{array}$} & 1 & 28.34 & 10189.24 & 4834.62 & 5354.62 & 0.90 & 9700.93 & 4881.12 & 4819.82 & 1.01 \\
\hline & 2 & 25.26 & 6289.78 & 3107.79 & 3181.99 & 0.98 & 6120.15 & 3105.81 & 3014.34 & 1.03 \\
\hline & 3 & 25.86 & 6636.13 & 3176.43 & 3459.70 & 0.92 & 6625.97 & 3397.38 & 3228.58 & 1.05 \\
\hline & 4 & 26.89 & 8798.45 & 3405.81 & 5392.64 & 0.63 & 8403.83 & 3146.95 & 5256.89 & 0.60 \\
\hline & 5 & 24.96 & 9205.62 & 4351.17 & 4854.46 & 0.90 & 9081.27 & 4219.87 & 4861.41 & 0.87 \\
\hline & 6 & 23.26 & 3688.47 & 1296.47 & 2392.00 & 0.54 & 3685.56 & 1431.03 & 2254.54 & 0.63 \\
\hline & 7 & 25.31 & 5323.34 & 2118.82 & 3204.51 & 0.66 & 5303.71 & 1991.90 & 3311.81 & 0.60 \\
\hline & 8 & 24.62 & 8224.90 & 3234.54 & 4990.36 & 0.65 & 7888.13 & 3398.49 & 4489.63 & 0.76 \\
\hline & 9 & 29.05 & 10393.41 & 4707.67 & 5685.74 & 0.83 & 10168.08 & 4423.34 & 5744.74 & 0.77 \\
\hline & 10 & 25.26 & 10814.57 & 5605.53 & 5209.04 & 1.08 & 10161.73 & 5432.46 & 4729.28 & 1.15 \\
\hline & 11 & 26.61 & 8872.31 & 4236.79 & 4635.52 & 0.91 & 8788.12 & 4274.02 & 4514.10 & 0.95 \\
\hline & 12 & 24.61 & 8852.70 & 4623.16 & 4229.55 & 1.09 & 8799.24 & 4463.19 & 4336.04 & 1.03 \\
\hline & 13 & 22.72 & 2385.33 & 980.28 & 1405.04 & 0.70 & 2422.08 & 991.43 & 1430.65 & 0.69 \\
\hline & 14 & 22.41 & 4201.65 & 1960.28 & 2241.37 & 0.87 & 4284.74 & 2050.37 & 2234.38 & 0.92 \\
\hline & 15 & 22.65 & 3427.55 & 935.59 & 2491.96 & 0.38 & 3357.22 & 958.63 & 2398.59 & 0.40 \\
\hline & 16 & 24.62 & 4532.13 & 2023.13 & 2509.00 & 0.81 & 4450.57 & 2048.65 & 2401.92 & 0.85 \\
\hline & 17 & 26.2 & 7820.87 & 3738.25 & 4082.62 & 0.92 & 7409.32 & 3989.96 & 3419.37 & 1.17 \\
\hline \multirow{2}{*}{$\mathrm{n}=17$} & \multirow{2}{*}{$\mathrm{M} \pm \mathrm{SD}$} & 25.21 & 7038.61 & 3196.25 & 3842.36 & 0.81 & 6861.80 & 3188.51 & 3673.30 & 0.85 \\
\hline & & \pm 1.88 & \pm 2690.45 & \pm 1441.97 & \pm 1330.72 & \pm 0.19 & \pm 2544.28 & \pm 1390.71 & \pm 1265.74 & \pm 0.85 \\
\hline \multirow{17}{*}{$\begin{array}{c}\text { Observer } \\
2\end{array}$} & 1 & 28.34 & 10053.24 & 4895.13 & 5158.12 & 0.95 & TAT & VAT & SAT & 1.08 \\
\hline & 2 & 25.26 & 6386.32 & 3094.86 & 3291.46 & 0.94 & 9475.93 & 4911.30 & 4564.64 & 0.96 \\
\hline & 3 & 25.86 & 6503.51 & 3160.56 & 3342.94 & 0.95 & 6030.61 & 2958.23 & 3072.38 & 0.93 \\
\hline & 4 & 26.89 & 8580.30 & 3336.29 & 5244.02 & 0.64 & 6118.89 & 2951.46 & 3167.43 & 0.53 \\
\hline & 5 & 24.96 & 9011.38 & 4292.15 & 4719.23 & 0.91 & 8585.16 & 2966.28 & 5618.88 & 0.91 \\
\hline & 6 & 23.26 & 3534.70 & 1202.48 & 2332.22 & 0.52 & 8678.61 & 4131.17 & 4547.44 & 0.58 \\
\hline & 7 & 25.31 & 4868.30 & 1929.32 & 2938.97 & 0.66 & 3175.11 & 1159.29 & 2015.81 & 0.61 \\
\hline & 8 & 24.62 & 8162.04 & 3121.37 & 5040.67 & 0.62 & 5096.77 & 1938.94 & 3157.83 & 0.83 \\
\hline & 9 & 29.05 & 9841.76 & 4435.28 & 5406.48 & 0.82 & 7713.21 & 3493.49 & 4219.72 & 0.75 \\
\hline & 10 & 25.26 & 9854.82 & 5098.26 & 4756.57 & 1.07 & 9805.05 & 4194.19 & 5610.86 & 1.10 \\
\hline & 11 & 26.61 & 8740.65 & 4104.12 & 4636.53 & 0.89 & 9750.10 & 5104.78 & 4645.32 & 0.94 \\
\hline & 12 & 24.61 & 8394.89 & 4358.13 & 4036.76 & 1.08 & 8499.22 & 4128.31 & 4370.92 & 1.15 \\
\hline & 13 & 22.72 & 2236.50 & 915.59 & 1320.91 & 0.69 & 8219.00 & 4392.20 & 3826.80 & 0.75 \\
\hline & 14 & 22.41 & 4169.01 & 1923.39 & 2245.62 & 0.86 & 2221.13 & 948.76 & 1272.37 & 1.09 \\
\hline & 15 & 22.65 & 3268.76 & 887.65 & 2381.11 & 0.37 & 4006.32 & 2088.80 & 1917.52 & 0.44 \\
\hline & 16 & 24.62 & 4755.37 & 2229.48 & 2525.89 & 0.88 & 3387.82 & 1032.44 & 2355.38 & 0.81 \\
\hline & 17 & 26.2 & 7655.50 & 3701.23 & 3954.27 & 0.94 & 4468.25 & 2004.26 & 2463.99 & 1.20 \\
\hline $\mathrm{n}=17$ & $\mathrm{M} \pm \mathrm{SD}$ & $\begin{array}{c}25.21 \\
\pm 1.88\end{array}$ & $\begin{array}{c}6824.53 \\
\pm 2563.74\end{array}$ & $\begin{array}{c}3099.13 \\
\pm 1374.13\end{array}$ & $\begin{array}{c}3725.40 \\
\pm 1276.14\end{array}$ & $\begin{array}{c}0.81 \\
\pm 0.20\end{array}$ & $\begin{array}{c}6632.52 \\
\pm 2504.20\end{array}$ & $\begin{array}{c}3088.66 \\
\pm 1363.53\end{array}$ & $\begin{array}{c}3543.86 \\
\pm 1282.29\end{array}$ & $\begin{array}{c}0.86 \\
\pm 0.86\end{array}$ \\
\hline
\end{tabular}

Note. BMI: body mass index, CT: computed tomography, MRI: magnetic resonance imaging, TATV: total adipose tissue volume, VATV: visceral adipose tissue volume, SATV: subcutaneous adipose tissue volume, $\mathrm{M} \pm \mathrm{SD}$ : mean \pm standard deviation, unit: cubic centimeters $\left(\mathrm{cm}^{3}\right)$. 
ments by $\mathrm{CT}$ and MRI imaging was examined by simple regression analysis in which the adipose tissue volume measured by $\mathrm{CT}$ from each part was set as an independent variable and the adipose tissue volume measured by MRI was set as a dependent variable. In addition, using the Bland-Altman plot, the degree of agreement between the two imaging methods was evaluated, in which the tolerance limit of errors (limit of agreement) between the two measurement values by $\mathrm{CT}$ and MRI was defined as mean \pm 1.96 standard deviation (Bland-Altman plot analysis is a statistical method for comparing two measurement methods, in which the degree of agreement between the measurements by an existing method and a new method is examined and thus, whether the new measurement method can replace the existing measurement method is analyzed [28]).

SPSS for Windows 17.02 (SPSS Inc., Chicago, IL, USA) was used for all the statistical analysis where $p<0.05$ was considered to be statistically significant.

\section{Results}

3.1. The general characteristics of the subjects and the measured adipose tissue volume

The mean age of the subjects was $35.9 \pm 5.3$ (range 26-
43) years, mean height was $170.47 \pm 3.45 \mathrm{~cm}$, mean weight $73.3 \pm 5.4 \mathrm{~kg}$ and mean BMI was $25.21 \pm 1.9 \mathrm{~kg} /$ $\mathrm{m}^{2}$. The adipose tissue volume from each part and the ratio of its distribution measured by two observers using $\mathrm{CT}$ and MR images are in Table 1.

The ratio of the difference in the measurement values by MRI using $\mathrm{CT}$ as a reference by observer is as follows (Table 2).

For Observer 1, the mean \pm standard deviation (minimum, maximum) values of TATV, VATV and SATV were -1.96 $\pm 2.27 \%(-6.04,1.98), 0.66 \pm 4.92 \%(-7.6,10.38)$, and $-3.99 \pm 5.16 \%(-16.25,3.35)$, respectively. For Observer 2 , they were $-2.76 \pm 3.60 \%(-10.17,4.69), 0.51 \pm 7.50$ $\%(-11.09,16.31),-5.13 \pm 6.96 \%(-16.29,7.45)$, respectively. Including both observers, the ratio of the difference had a minimum of -16.29 and a maximum of $16.31 \%$.

3.2. Evaluation for the correlation and degree of agreement of the measurements by observer

Using Spearman test, the correlation between the measured adipose tissue volume by $\mathrm{CT}$ and MRI in each observer was analyzed. The results showed that for Observer 1, the correlation coefficient $\mathrm{R}$ values of TATV, VATV and SATV were $0.995,0.978$ and 0.968 , respectively, For Observer 2, the $\mathrm{R}$ values were $0.968,0.922$

Table 2. The ratio of difference in the measured adipose tissue volume by MRI using CT as a reference by Observer 1 and 2 , respectively.

\begin{tabular}{|c|c|c|c|c|c|c|c|}
\hline \multirow{2}{*}{\multicolumn{2}{|c|}{$\begin{array}{l}\text { No. of } \\
\text { subjects }\end{array}$}} & \multicolumn{3}{|c|}{ Observer 1} & \multicolumn{3}{|c|}{ Observer 2} \\
\hline & & TATV & VATV & SATV & TATV & VATV & SATV \\
\hline \multirow{16}{*}{$\begin{array}{l}\text { The ratio of } \\
\text { difference for } \\
\text { CT and MRI } \\
(\%)\end{array}$} & 1 & -4.79 & 0.96 & -9.99 & -5.74 & 0.33 & -11.51 \\
\hline & 2 & -2.70 & -0.06 & -5.27 & -5.57 & -4.41 & -6.66 \\
\hline & 3 & -0.15 & 6.96 & -6.68 & -5.91 & -6.62 & -5.25 \\
\hline & 4 & -4.49 & $-7.60 \mathrm{~min}$ & -2.52 & 0.06 & $-11.09 \mathrm{~min}$ & 7.15 \\
\hline & 5 & -1.35 & -3.02 & 0.14 & -3.69 & -3.75 & -3.64 \\
\hline & 6 & -0.08 & $10.38 \max$ & -5.75 & $-10.17 \mathrm{~min}$ & -3.59 & -13.57 \\
\hline & 7 & -0.37 & -5.99 & $3.35 \mathrm{max}$ & $4.69 \mathrm{max}$ & 0.50 & $7.45 \max$ \\
\hline & 8 & -4.09 & 5.07 & -10.03 & -5.50 & 11.92 & $-16.29 \mathrm{~min}$ \\
\hline & 9 & -2.17 & -6.04 & 1.04 & -0.37 & -5.44 & 3.78 \\
\hline & 10 & $-6.04 \mathrm{~min}$ & -3.09 & -9.21 & -1.06 & 0.13 & -2.34 \\
\hline & 11 & -0.95 & 0.88 & -2.62 & -2.76 & 0.59 & -5.73 \\
\hline & 13 & 1.54 & 1.14 & 1.82 & -0.69 & 3.62 & -3.67 \\
\hline & 14 & $1.98 \mathrm{max}$ & 4.60 & -0.31 & -3.90 & 8.60 & -14.61 \\
\hline & 15 & -2.05 & 2.46 & -3.75 & 3.64 & $16.31 \max$ & -1.08 \\
\hline & 16 & -1.80 & 1.26 & -4.27 & -6.04 & -10.10 & -2.45 \\
\hline & 17 & -5.26 & 6.73 & $-16.25 \mathrm{~min}$ & -1.75 & 10.86 & -13.55 \\
\hline \multirow{2}{*}{$\mathrm{n}=17$} & $\mathrm{M}$ & -1.96 & 0.66 & -3.99 & -2.76 & 0.51 & -5.13 \\
\hline & $\pm \mathrm{SD}$ & \pm 2.27 & \pm 4.92 & \pm 5.16 & $\pm \mathbf{3 . 6 0}$ & \pm 7.50 & \pm 6.96 \\
\hline
\end{tabular}

Note. TATV: Total adipose tissue volume, VATV: visceral adipose tissue volume, SATV: subcutaneous adipose tissue volume, $\mathrm{M} \pm \mathrm{SD}$ : mean \pm standard deviation. min: minimum, max: maximum, unit: percentage $(\%)$. 
Table 3. Spearman correlation coefficients between CT and MRI according to distribution of adipose tissue volume measured by Observer 1 and 2, respectively.

\begin{tabular}{cccccc}
\hline \hline \multirow{2}{*}{$\begin{array}{c}\text { Distribution of } \\
\text { adipose tissue } \\
\text { volume }\end{array}$} & \multicolumn{2}{c}{$\begin{array}{c}\text { Adipose tissue volume measured } \\
\text { by Observer 1 }\end{array}$} & & \multicolumn{2}{c}{$\begin{array}{c}\text { Adipose tissue volume measured } \\
\text { by Observer 2 }\end{array}$} \\
\cline { 2 - 3 } TATV & Correlation coefficients & p-Value & & Correlation coefficients & p-Value \\
VATV & 0.995 & $<0.01$ & 0.968 & $<0.01$ \\
SATV & 0.978 & $<0.01$ & 0.922 & $<0.01$ \\
VATV/SATV & 0.968 & $<0.01$ & 0.956 & $<0.01$ \\
\hline
\end{tabular}

Note. TATV: total adipose tissue volume, VATV: visceral adipose tissue volume, SATV: subcutaneous adipose tissue volume.

Table 4. Intra-class correlation coefficients between Observer 1 and 2 according to distribution of adipose tissue volume measurement using by $\mathrm{CT}$ and MRI.

\begin{tabular}{cccccc}
\hline \hline \multirow{2}{*}{$\begin{array}{c}\text { Distribution of } \\
\text { adipose tissue volume }\end{array}$} & \multicolumn{2}{c}{ Adipose tissue volume measured using by CT } & & \multicolumn{2}{c}{ Adipose tissue volume measured using by MRI } \\
\cline { 2 - 2 } & $\begin{array}{c}\text { Intra-class correlation } \\
\text { average measure }\end{array}$ & p-Value & & $\begin{array}{c}\text { Intra-class correlation } \\
\text { average measure }\end{array}$ & p-Value \\
TATV & 0.990 & $<0.01$ & 0.978 & $<0.01$ \\
VATV & 0.994 & $<0.01$ & 0.963 & $<0.01$ \\
SATV & 0.983 & $<0.01$ & 0.987 & $<0.01$ \\
\hline
\end{tabular}

Note. TATV: total adipose tissue volume, VATV: visceral adipose tissue volume, SATV: subcutaneous adipose tissue volume.

and 0.956, also respectively. Measurements by the observers showed a highly statistically significant correlation $(p<$ 0.05) (Table 3).

Using intra-class correlation coefficient (ICC), the degree of agreement of the measured adipose tissue volume between observers was verified. The results showed that for CT, the correlation coefficient $\mathrm{R}$ values of TATV, VATV and SATV were 0.990, 0.994 and 0.983, respectively, and for MRI, the R values were $0.978,0.963$ and 0.987 , respectively, which showed a stronger correlation than CT and the degree of the inter-observer agreement was highly statistically significant $(p<0.05)$ (Table 4$)$.

\subsection{Evaluation for the correlation and the degree of} agreement of the measured values by image acquisition method

By performing simple regression analysis, the correlation of the adipose tissue volume measured by CT and MRI imaging methods was analyzed and the results showed that for Observer 1 , the correlation coefficient $\mathrm{R}$ and coefficient of determination $\mathrm{R}$ squared $\left(\mathrm{R}^{2}\right)$ values of TATV, VATV and SATV were 0.997:0.994, 0.992:0.985, and 0.980:0.960, respectively. For Observer 2, the values were 0.975:0.950, 0.952:0.905, and 0.970:0.941, respectively. The correlation between the both imaging methods was highly statistically significant $(p<0.05)$ (Fig. 4).

Using Bland-Altman plot, the degree of agreement of the adipose tissue volume measured by MRI using the CT as a reference was analyzed, and the result showed that the differences in the values measured by both Observer 1 and 2 were within the tolerance limits of errors (mean \pm $1.96 \mathrm{SD})$ in nearly all subjects $(p<0.05)$ (Fig. 5).

Tolerance limit of errors for TATV, VATV and SATV in Observer 1 were $-269.96 \sim 676.52 \mathrm{~cm}^{3},-230.98 \sim 461.54$ $\mathrm{cm}^{3}$, and $-489.24 \sim 665.24 \mathrm{~cm}^{3}$, respectively. The tolerance limit of errors for TATV, VATV and SATV in Observer 2 were $-972.01 \sim 1269.51 \mathrm{~cm}^{3},-536.07 \sim 1133.37 \mathrm{~cm}^{3}$ and $-784.07 \sim 484.29 \mathrm{~cm}^{3}$, respectively. The tolerance limit for errors of Observer 2 tended to be slightly larger than that for Observer 1.

\section{Discussion}

Obesity refers to a state of increased and excess body fat, more so than for a normal condition, and it plays an important factor in chronic diseases. As to the distribution of fat in obesity, the patterns of its anatomical distribution can vary among people who have the same amount of total body fat, but it leads to differences in prevalence of the diseases as the pattern of the body fat distribution is clinically important [29].

According to the guidelines from the World Health Organization (WHO) [30] and the National Institutes of Health $(\mathrm{NIH})$ [31], the health risks vary depending on the degree of abdominal obesity with the same degree of obesity, and in particular, abdominal obesity increases the 

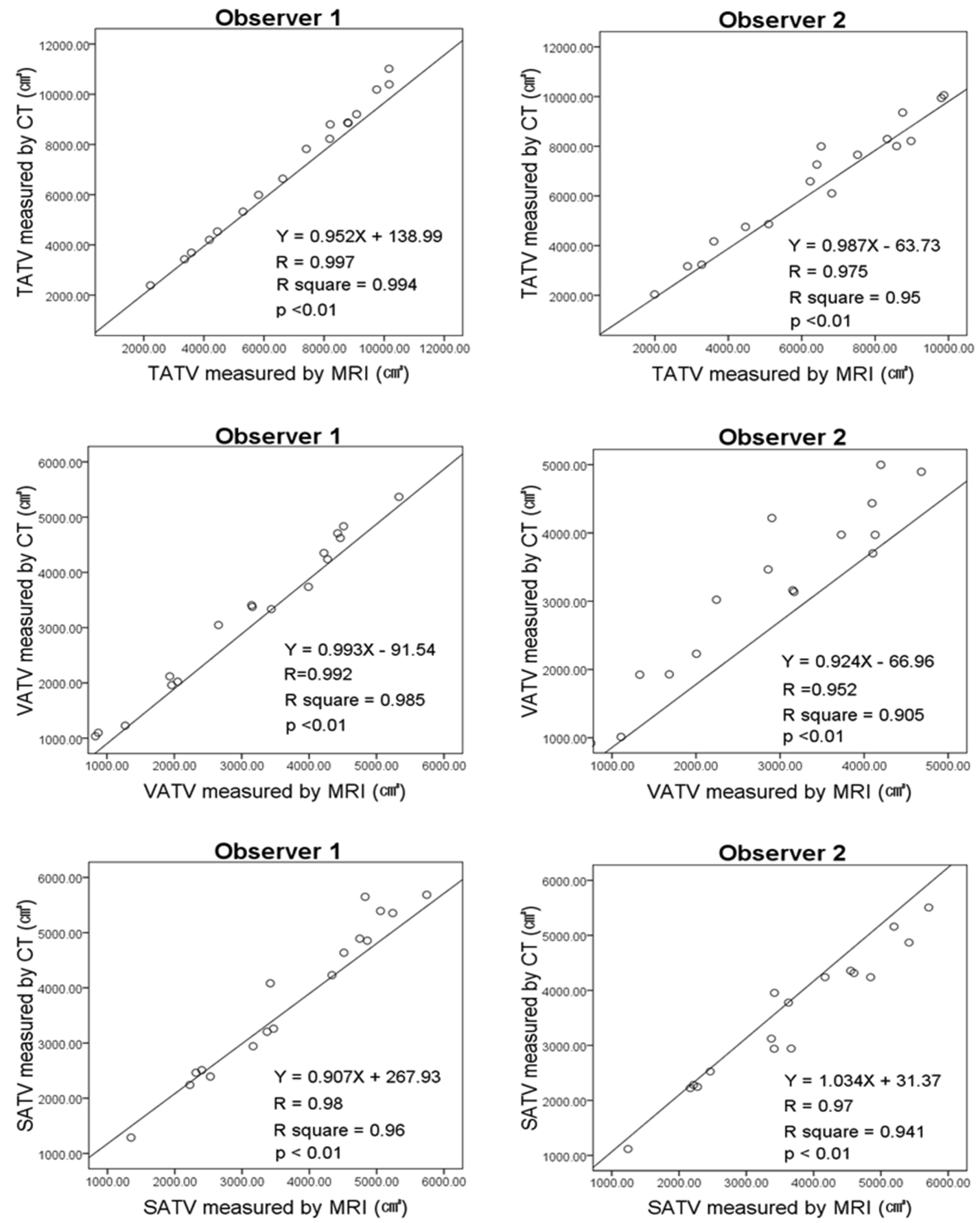

Fig. 4. Simple regressions analysis to evaluate the correlation between CT and MRI measurement of adipose tissue volume by Observer 1 (left column) and Observer 2 (right column). The straight lines represent the regression functions between CT and MRI. Graphs of regressions analysis of TATV (top row), VATV (middle row), and SATV (bottom row) measurements from CT versus MRI; $p$-value was less than 0.05 . Note. CT: computed tomography, MRI: magnetic resonance imaging, TATV: total adipose tissue volume, VATV: visceral adipose tissue volume, SATV: subcutaneous adipose tissue volume.

prevalence of the metabolic syndrome accompanied by diabetes, high blood pressure, dyslipidemia and atherosclerotic diseases such as coronary heart disease [32, 33]. The fat distribution associated with abdominal obesity is divided into abdominal subcutaneous fat and visceral fat, of which visceral fat is rated to be clinically more important than subcutaneous fat [34]. The reason why visceral fat is more problematic is because the metabolic characteristics change depending on the area of adipose tissue distribution. The basal fat degradation rate of 

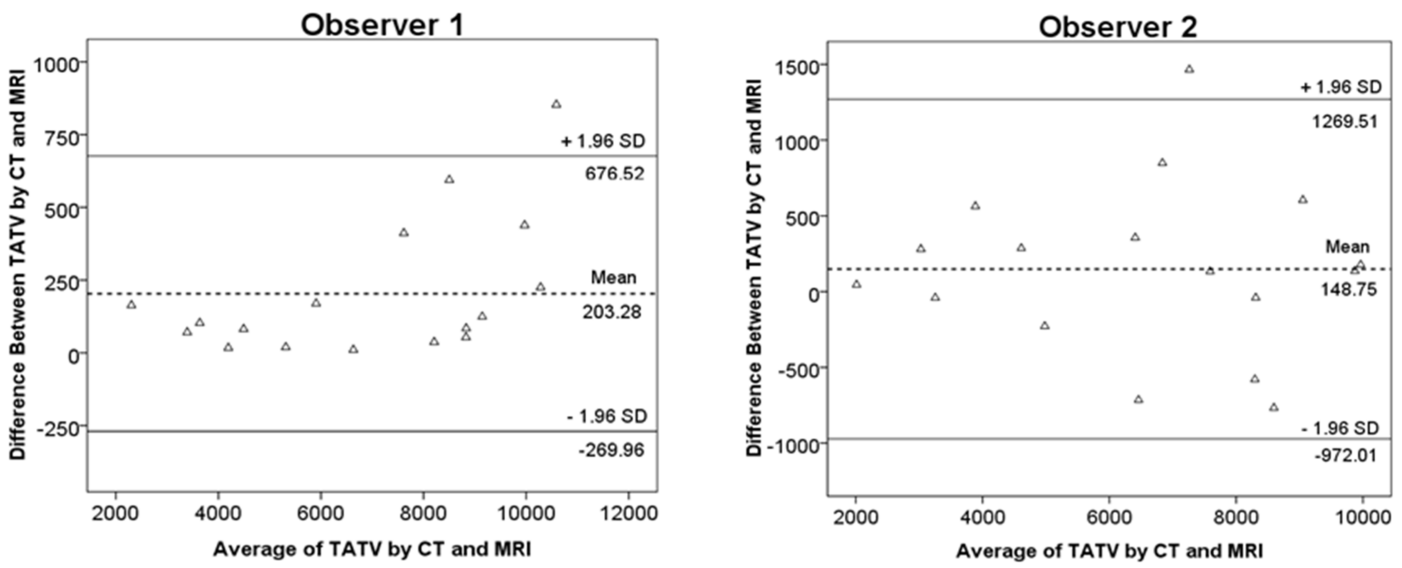

Observer 1
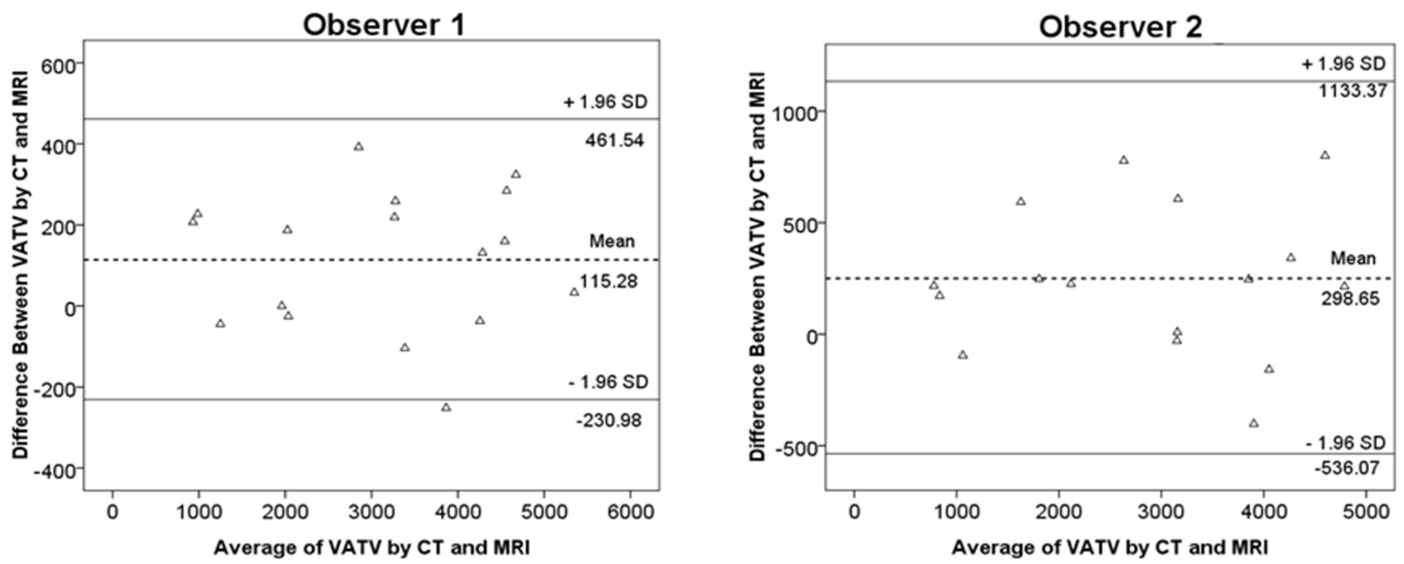

Observer 1
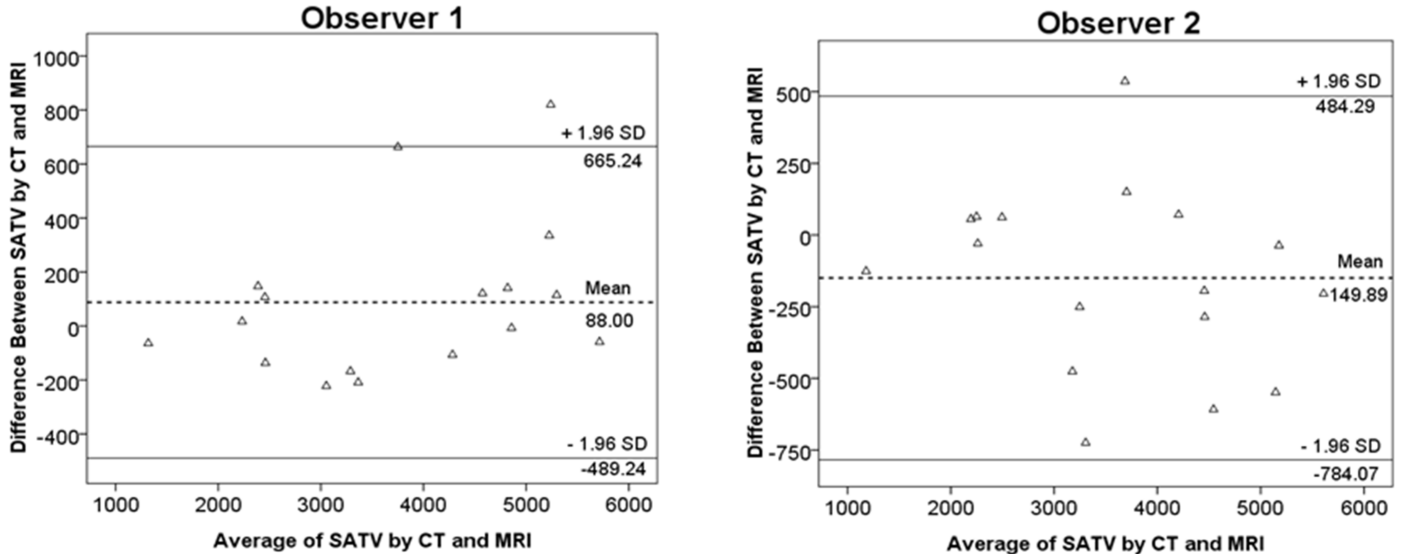

Fig. 5. Bland-Altman plot analysis to evaluate the agreement between adipose tissue volumes by CT and that MRI (left column, Observer 1; right column, Observer 2). Horizontal dotted lines are drawn at the mean difference between the two measures, and at the mean difference \pm 1.96 the standard deviation of the differences. Evaluating the agreement of TATV (top row), VATV (middle row), SATV (bottom row) measurements from MRI and CT scans; $p$-value was less than 0.05 . Note. CT: computed tomography, MRI: magnetic resonance imaging, TATV: total adipose tissue volume, VATV: visceral adipose tissue volume, SATV: subcutaneous adipose tissue volume.

visceral fat cells is higher than that of subcutaneous fat cells [35], and visceral fat cells are known to be less sensitive to the suppressive action of insulin for fat degradation. Also, because the level of leptin secretion is lower in the visceral adipose tissues than the subcutaneous adipose tissues, changes in the body fat distribution from subcutaneous fat to more visceral fat results in a less effective regulation of food intake induced by leptin. The 
increase in visceral fat raises the concentration of free fatty acids in the hepatic portal blood [36], which in turn is reported to lower the insulin sensitivity in the liver. In particular, there are reports that the degree of visceral fat accumulation in Asians is relatively higher in spite of their less severe obesity than the Westerners, which leads to high risk of the diseases [37, 38]. In recent years, due to multiple reasons such as Westernization of eating habits, excessive intake of nutrition and the lack of exercise in the living conditions, the population with intraabdominal fat accumulation-related obesity is also increasing in Korea, and accordingly the prevalence of the metabolic syndrome tends to be high [39]. For this reason, many studies on the indicators for evaluating the body fat distribution that can be applied in the clinical practice are currently ongoing.

For measurement of body fat distribution, several methods are being used clinically including anthropometry such as waist circumference (WC) and waist to hip circumference ratio (WHR), BIA, DXA, ultrasonography (US), CT, MRI, etc. [7-14, 40]. Evaluation by anthropometric methods is the easiest way to measure abdominal obesity and visceral fat, in which waist circumference and waist to hip circumference ratio have been commonly used. However, these physical measurements cannot distinguish between subcutaneous fat and visceral fat, and given that the difference in visceral fat can be great for two individuals even with the same waist circumference and waist to hip circumference ratio, it is difficult to accurately and quantifiably use these measures as indicators of visceral fat $[8$, 41]. The fat measurement method using BIA has a relatively high reproducibility and easy accessibility, but it is a comprehensive obesity measuring method to measure the sum total fat that is distributed in the body by measuring the biometric resistance [42], and is rather inadequate for evaluating abdominal visceral fat. Using DXA method, not only the amount of total body fat, but also visceral fat can be measured relatively accurately [10], but it was reported that its effectiveness for assessing visceral fat rather fell short in comparison to anthropometry for waist circumference and abdominal back length measurement [43], and it also has a concern for potential radiation exposure, which makes it difficult to clinically use it with ease.

As a direct and quantitatively method of measuring abdominal fat, medical imaging using a CT or MRI is available $[17,44]$. The fat measuring method using CT distinguishes abdominal visceral fat and subcutaneous fat by digitizing the Hounsfield unit (HU) of the adipose tissue, through which visceral adipose tissue is measured directly and quantification is possible, thus making it the most accurate method for measuring fat content $[15,16]$. However, for reasons such as exposure to radiation, there are limitations in applying this method for repeated measurements for a length of time for the purpose of clinical research, and this includes concern for radiation-sensitive subjects such as children and women of childbearing age. Thus, for accurate assessment of fat distribution in the body, there is a need for a non-invasive method without radiation exposure. For these reasons, the fat measuring method using MRI has been recognized as one of the ideal methods for assessment of body fat distribution [14].

MRI can deliver various tissue contrasts according to the pulse sequence and imaging parameters used, making it particularly suitable for imaging tissues such as fat or water. For selective imaging of the adipose tissue, techniques such as spin echo T1 weighted imaging, FLAIR (fluid attenuated inversion recovery) and CHESS (chemical shift selective saturation) have been commonly used. Because these methods take a long time for acquisition and are sensitive to the uniformity of the magnetic field, it is rather difficult to analyze the abdominal tissues quantitatively through imaging due to the changes in the signal intensity caused by breathing or peristalsis-related organ movements and the differences in the magnetic susceptibility at the air-tissue interface caused by air in the intestinal tract. Furthermore, unlike the HU value of CT, no standardized criteria are available for range selection of the fat signal intensity, which makes the measuring process complicated with a wide margin of errors for the inter- or intra-rater measurement $[45,46]$.

Recently, an abdominal imaging method emphasizing fat or water signals using the DIXON technique is being used popularly [47]. The DIXON technique proposed by Dixon in 1984 is a method to use the phase differences between the hydrogen-magnetic phases of fat and water, in which the signals when the fat phase and water phase are in phase and out of phase, respectively, are obtained and then using the sum and difference thereof, images consisting only of water (water only) or fat (fat only) can be acquired respectively. This can be briefly described by the following formula.

$$
\begin{aligned}
& \text { "In phase" : water + fat, "out of phase" : water - fat } \\
& 1 / 2[\text { In phase }+ \text { out of phase }] \\
& =1 / 2[(\text { Water }+ \text { Fat })+(\text { Water }- \text { Fat })] \\
& =1 / 2[2 \text { Water }]=\text { Water only } \\
& 1 / 2[\text { In phase }- \text { out of phase }] \\
& =1 / 2[(\text { Water }+ \text { Fat })-(\text { Water }- \text { Fat })] \\
& =1 / 2[2 \mathrm{Fat}]=\text { Fat only }
\end{aligned}
$$


The original DIXON techniques in theory required perfect uniformity of the magnetic field with no change in the local magnetic susceptibility, and this led to unsuccessful generation of effective images. In recent years, thanks to popularization of the MRI system equipped with a uniform magnetic field and improved image processing algorithms, a variety of modified DIXON imaging techniques acquiring images from two or more signals are now being universalized. Therefore, the technique is usefully employed for quantitative analysis of fat, as it is possible to obtain images that are relatively less sensitive to the difference in the magnetic susceptibility caused by a non-uniform magnetic field and to changes in the signal strength. Taking advantage of these properties, comparative studies such as quantitative evaluation of hepatic steatosis have been actively conducted [24, 26, 48].

Currently, for clinical fat measurement using CT, due to the concerns of excessive radiation exposure, usually the area is measured using a single cross-section (single slice) image across around the belly button $\left(4^{\text {th }} \sim 5^{\text {th }}\right.$ lumbar $)$ anatomically and its distribution ratio is calculated. However, this measurement method using a single crosssection raises concerns of low accuracy and reproducibility due to the structural movements within the abdominal cavity caused by the dispersion of gravity over the body weight while lying on the examination table or changes in the abdominal pressure depending on the state of breathing. According previous studies, since the distribution of abdominal fat showed differences within or between subjects, reportedly, it is desirable to measure it using multi-slice images rather than a single cross-section (single slice) of a specific part [49-51].

For most of the studies on measurement of abdominal fat using MR, to correlate among the anthropometry methods performed conventionally, the ratio of adipose tissue was mainly measured from the cross-section crossing the navel area $\left(4^{\text {th }} \sim 5^{\text {th }}\right.$ lumbar $)$ and that can be measured easily [52]. However, Warren et al. [51] reported in a study on comparative body fat measurements using a single abdominal cross-section and several cross-sections, differences in the anatomical fat distribution by gender or age required corrections for the measurement method on a specific cross-section. Nakai et al. [53] reported that in a body fat measuring method through an automatic measurement program using a $10 \mathrm{~mm}$ thick cross-section, the margin of the errors between the measurements of visceral adipose tissue and subcutaneous adipose tissue was large in the repeated measurements due to the movement of the abdominal organs and thus, the reproducibility of the measurement became statistically significant only when at least 7 cross-sections were taken; these included
3 upper cross-sections and 3 lower cross-sections with a navel cross-section as the center.

In this study, the adipose tissue measuring method using only a fraction of the number of cross-sectional images which were presented as limitations in previous studies was excluded and the adipose tissue content was measured and compared using whole abdominal volume images over the entire abdomen. The 3D gradient dual echo 2 point DIXON (GE termed LAVA-flex) technique used in this study acquires signals using the phase differences between fat and water depending on two echo times of 1.3 and $2.6 \mathrm{~ms}$, from which four kinds of images, "water-only," "fat-only," "in-phase" and "out-of-phase" are generated simultaneously through a reconstruction algorithm to get the imaging information of contrasts from a variety of tissues [26].

By adjusting image acquisition parameters, it is possible to obtain a voluminal image across the entire abdominal region by a single breath, which makes it possible to minimize the changes in the signal intensity due to the movement caused by breathing or peristalsis or the differences in the magnetic susceptibility of the air in the intestines. Therefore, measurement of fat using the "fatonly" image can be measured quantitatively with more accuracy than several other MR adipose tissue imaging methods previously introduced. Moreover, in addition to the information of the amount of body adipose tissue, abnormal conditions of the internal organs can be determined through the contrast of a variety of soft tissues [47, 54]. Even in a subject of this study, intra-hepatic abnormal lesion was found in the "water-only" image, which led to a definite diagnosis through additional medical interventions (Fig. 6).

According to this study, the measurement of adipose tissue volume using MRI showed a statistically highly significant result when compared with the values measured by $\mathrm{CT}$ as reference. Using Spearman test and ICC test, the measured values depending on observers demonstrated a very high correlation and degree of agreement through which the reproducibility could be verified $(p<0.05)$. The correlation and the degree of agreement between the both imaging methods were evaluated, and the result showed that according to regression analysis, the coefficient of determination $\left(\mathrm{R}^{2}\right)$ between the two imaging methods was found to be at least $90 \%$ (minimum $90.5 \%$ and maximum $99.4 \%$ ), which was very high and the degree of agreement of the measurements obtained by BlandAltman plot was found to be mostly distributed within mean \pm 1.96 standard deviation, which is the tolerance limit of errors, which suggests that it is a fully replaceable method. 


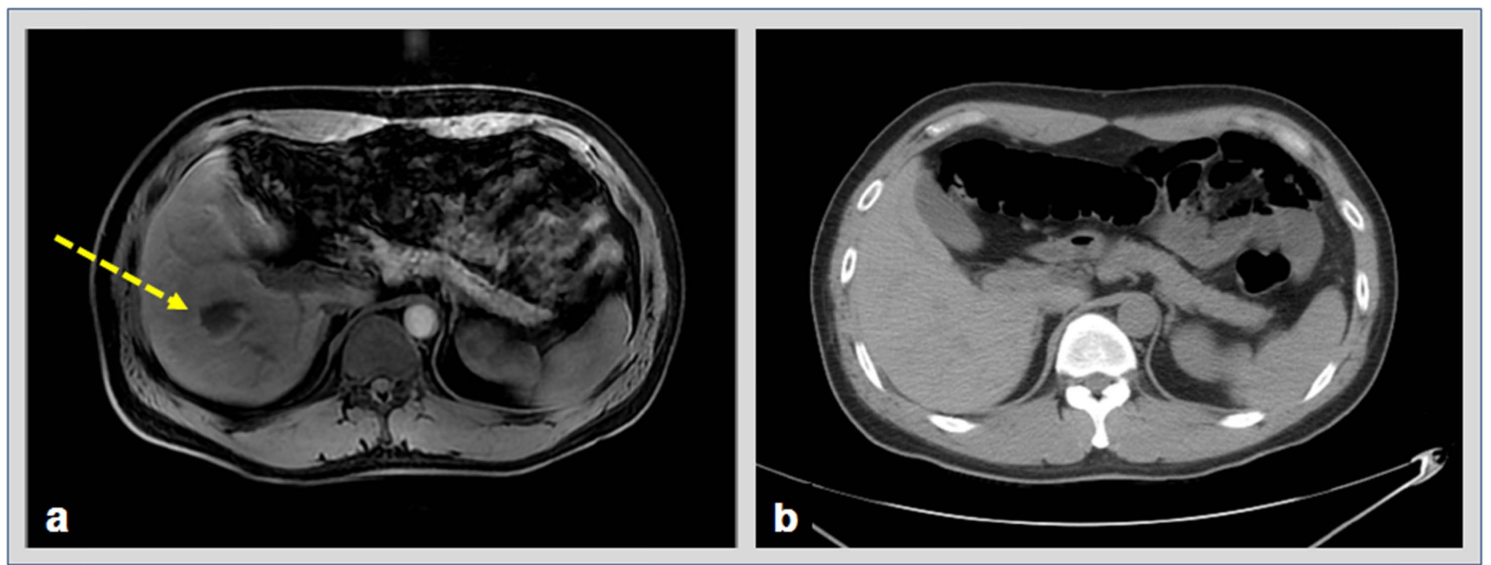

Fig. 6. (Color online) A subject examination case. Intra-hepatic abnormal lesion (dotted arrow) on water-only image of magnetic resonance imaging (a) but poor visualization of abnormal lesion on computed tomography image (b).

When the adipose tissue volume measurements, however, were compared in absolute values, the values measured by MRI were lower than those measured by CT as a whole. When setting the signal intensity range for adipose tissue in CT and MRI images, respectively, the investigators in this study referred to the image including the navel part to include the adipose tissue sufficiently. In this method, while adipose tissues are uniformly selected from the total volume images according to the setting of the $\mathrm{HU}$ value in CT, in case of MRI, as it is further from the center of the receiving coil, the signal intensity becomes reduced and the background noise and artifacts are increased; therefore, it is thought that these effects can give somewhat subjective and biased information to the observer when setting the range of signal intensity. In addition, when using 2-point DIXON imaging technique, it can be thought that the signal reduction due to the $\mathrm{T} 2 *$ effect resulted from the changes in the magnetic susceptibility such as abdominal organ peristalsis, blood flow and the air in the intestines might have been a factor to some extent. However, within the results of this study, it is difficult to prove the influence of those effects, and it is thought that its correlation needs to be verified through further studies.

One more thing to be noted through the results from this study is the ratio of visceral adipose tissue volume and subcutaneous adipose tissue volume (VATV/SATV). In a previous study on comparative measurement of the abdominal fat area by MRI and CT using spin echo T1 weighted technique, Yoon et al. [17] reported that the ratio of visceral adipose tissue volume and subcutaneous adipose tissue volume measured by MRI showed a lower accuracy than CT due to the ambiguity of standardization and setting in the range of the signal intensity and
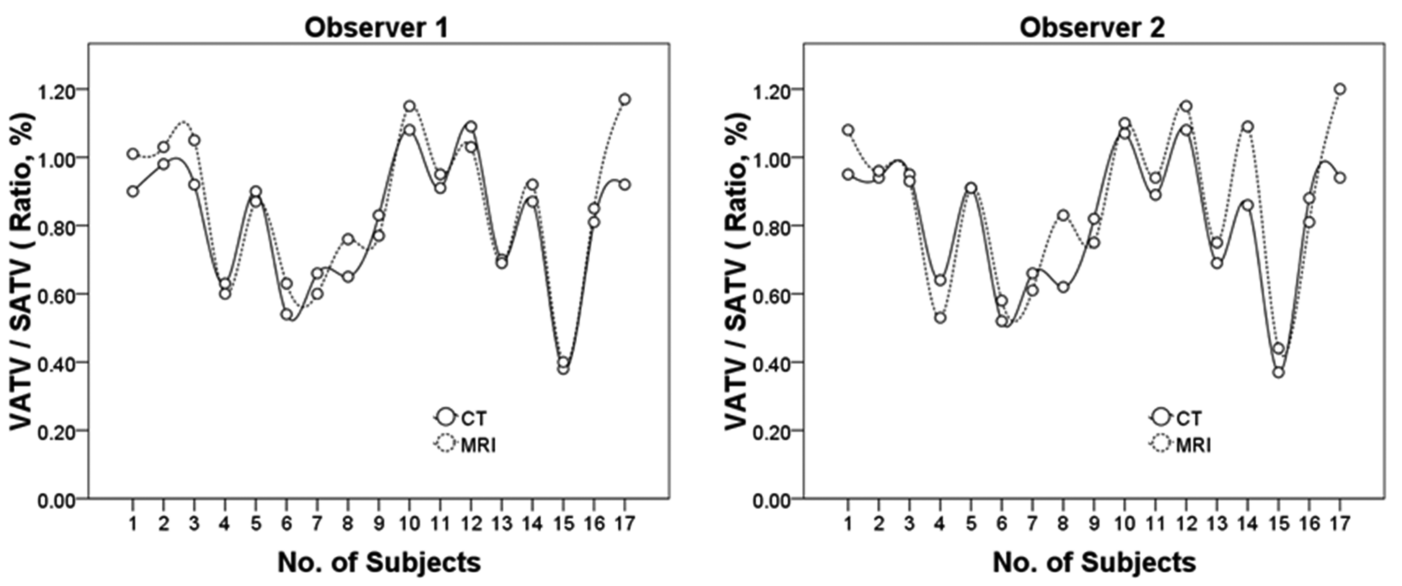

Fig. 7. Graph of VATV/SATV ratio between CT and MRI measured by Observer 1 (left) and Observer 2 (right). $p$-value was less than 0.05. Note. VATV: visceral adipose tissue volume, SATV: subcutaneous adipose tissue volume, CT: computed tomography, MRI: magnetic resonance imaging. 
reportedly the reproducibility was not satisfactory either. However, in this study, the measurement was made using the MR images consisting of only the fat signal ("fatonly") and even if the aforementioned absolute values of the adipose tissue volume were different in a quantitative sense, the ratio of measurements between the both imaging methods showed a very similar pattern (Fig. 7) with a very high statistically significant correlation, in which each correlation coefficient $\mathrm{R}$ value was 0.935 (Observer 1 ) and 0.848 (Observer 2$)$, respectively $(p<0.01)$. This is consistent with the hypothesis of 'accurate assessment of the distribution ratio rather than the total fat amount,' which was presumed in the planning stage of this study, and as mentioned at the beginning of this article, the ratio of fat distribution is the more important factor than the total body fat content for the clinical judgment [55], and therefore, these characteristics are thought to be helpful for analyzing their correlations with the pathogenic factors according to the ratio of fat distribution.

In addition, the investigators in this study statistically compared the relationship between BMI of the subjects and the VATV/SATV ratio measured by each imaging method through experiments. For Observer 1, the correlation coefficient $\mathrm{R}$ value of $\mathrm{CT}$ and BMI was 0.257 , the $\mathrm{R}$ value of MRI was 0.265 and for Observer 2, the $R$ value of CT was 0.303 and the R value of MRI was 0.108 , from which no statistically significant correlation was observed $(p>0.05)$. These results directly reflected the findings from a previous study showing that BMI is a meaningful index for whole body obesity, but it is not suitable for evaluation of abdominal obesity, especially of visceral fatrelated obesity [7].

The limitations of this study are as follows: the sample size of the study was small and the characteristics of the sample group was that it was comprised only of healthy adult males, thus gender and age and medical historyrelated variables were not considered. The pattern of the body fat accumulation is affected by hormone and genetic factors, which can lead to gender differences. For men, androgen insufficiency is known to be associated with central obesity such as abdominal obesity [56] and also for women, estrogen is known to play a role in the accumulation of fat in the buttocks [57]. In addition, fat distribution is also different according to age, for example, while the area of visceral fat in women tends to be increased significantly after menopause, it tends to be increased in proportion with the advance of age in men [21]. In consideration of these variables, a prospective study which can evaluate the accuracy is required in the future.

With all the results taken together, MR abdominal adipose volumetry using the technique of $3 \mathrm{D}$ gradient dual echo 2-point DIXON showed a very high level of concordance even when compared with the adipose tissue measuring method using $\mathrm{CT}$ as a reference, and it was confirmed that there was a statistically strong correlation between the two techniques. Thus, when compared with the conventional measurement methods, the MR technique is highly accurate and safe and the information on fat distribution can be verified directly and intuitively without concerns about radiation exposure. In addition, due to its wide range of choices for applicable subjects and less harmful effects to the human body by repeated measurements, the MR technique is also suitable for research purposes that require long-term observations. However, issues such as the higher cost than other conventional measurement methods and accessibility still need to be fully considered, when this technique is to be more widely applied.

\section{Conclusions}

The MR abdominal adipose tissue volumetry using 3D Gradient dual echo 2-point DIXON technique is thought to have a clinical significance as an ideal method for measuring adipose tissue volume, and it can provide more useful and accurate clinical information for management and evaluation of diseases such as obesity or metabolic syndrome, which are attracting a lot of social interest lately.

\section{References}

[1] H. K. Choi and E. S. Ford, Am. J. Med. 120, 442 (2007).

[2] S. M. Grundy, J. Am. Coll. Cardiol. 47, 1093 (2006).

[3] N. Abate, Diabetes Care. 19, 292 (1996).

[4] S. Fujioka, Y. Matsuzawa, K. Tokunaga, and S. Tarui, Metabolism. 36, 54 (1987).

[5] D. Blair, J. P. Habicht, E. A. Sims, D. Sylwester, and S. Abraham, Am. J. Epidemiol. 119, 526 (1984).

[6] A. H. Kissebah, N. Vydelingum, R. Murray, D. J. Evanse, R. K. Kalkhoff, and P. W. Adams, J. Clin. Endocrinol. Metab. 54, 254 (1982).

[7] I. Janssen, S. B. Heymsfield, D. B. Allison, D. P. Kotler, and R. Ross, Am. J. Clin. Nutr. 75, 683 (2002).

[8] M. C. Pouliot, J. P. Despres, S. Lemieux, S. Moorjani, C. Bouchard, A. Tremblay, A. Nadeau, and P. J. Lupien, Am. J. Cardiol. 73, 460 (1994).

[9] S. H. Han, S. Y. Lee, K. N. Kim, and S. M. Yoo, Korean J. Obes. 15, 213 (2006).

[10] E. Bertin, C. Marcus, J. C. Ruiz, J. P. Eschard, and M. Leutenegger, Int. J. Obes. Relat. Metab. Disord. 24, 263 (2000).

[11] T. Nakamura and T. Yoshizumi, Nippon Rinsho. 64(Suppl. 
9), 476 (2006).

[12] S. Rossner, W. J. Bo, E. Hiltbrandt, W. Hinson, N. Karstaedt, P. Santago, W. T. Sobol, and J. R. Crouse, Int. J. Obes. 14, 893 (1990).

[13] Y. L. Chan, S. S. Leung, W. W. Lam, X. H. Peng, and C. Metreweli, J. Pediatr. Child. Health. 34, 22 (1998).

[14] C. M. de Ridder, R. W. de Boer, J. C. Seidell, C. M. Nieuwenhoff, J. A. Jeneson, C. J. Bakker, M. L. Zonderland, and W. B. Erich, Int. J. Obes. 16, 443 (1992).

[15] T. Yoshizumi, T. Nakamura, M. Yamane, A. H. Islam, M. Menju, K. Yamasaki, T. Arai, K. Kotani, T. Funahashi, S. Yamashita, and Y. Matsuzawa, Radiology 211, 283 (1999).

[16] K. Tokunaga, Y. Matsuzawa, K. Ishikawa, and S. Tarui, Int. J. Obes. 7, 437 (1983).

[17] D. Y. Yoon, J. H. Moon, H. K. Kim, C. S. Choi, S. K. Chang, E. J. Yun, and Y. L. Seo, Acad Radiol. 15, 62 (2008).

[18] J. G. Terry, W. H. Hinson, G. W. Evans, P. J. Schreiner, and A. P. Hagaman, Crouse JR $3^{\text {rd }}$, Am. J. Clin. Nutr. 62, 297 (1995).

[19] P. J. Schreiner, J. G. Terry, G. W. Evans, and W. H. Hinson, Crouse JR $3^{\text {rd }}$, G. Heiss, Am. J. Epidemiol. 144, 335 (1996).

[20] R. Ross, K. D. Shaw, J. Rissanen, Y. Martel, J. D. Guise, and L. Avruch, Am. J. Clin. Nutr. 59, 1277 (1994).

[21] K. Kotani, K. Tokunga, S. Fujioka, T. Kobatake, Y. Keno, S. Yoshida, I. Shimomura, S. Tarui, and Y. Matsuzawa, Int. J. Obes. Relat. Metab. Disord. 18, 207 (1994).

[22] R. S. Schwartz, W. P. Shuman, V. L. Bradbury, K. C. Cain, G. W. Fellingham, J. C. Beard, S. E. Kahn, J. R. Stratton, M. D. Cerqueira, and I. B. Abrass, J. Gerontol. 45, 181 (1990).

[23] S. Mito, K. Ishizaka, M. Nakanishi, H. Sugimori, H. Hamaguchi, and T. Tsuzuki, Nihon Hoshasen Gijutsu Gakkai Zasshi. 67, 654 (2011).

[24] K. Ishizaka, N. Oyama, S. Mito, H. Sugimori, M. Nakanishi, T. Okuaki, H. Shirato, and S. Terae, Magn. Reson. Med. Sci. 10, 41 (2011).

[25] J. Machann, J. Magn. Reson. Imaging. 28, 543 (2008).

[26] J. Machann, Magn. Reson. Med. 52, 415 (2004).

[27] K. T. Bae, F. Zhu, A. B. Chapman, V. E. Torres, J. J. Grantham, L. M. Guay-Woodford, D. A. Baumgarten, B. F. King Jr, L. H. Wetzel, P. J. Kenney, M. E. Brummer, W. M. Bennett, S. Klahr, C. M. Meyers, X. Zhang, P. A. Thompson, and J. P. Miller, Clin. J. Am. Soc. Nephrol. 1, 64 (2006).

[28] J. M. Bland and D. G. Altman, Lancet. 1, 307 (1986).

[29] B. Larsson, K. Svardsudd, L. Welin, L. Wilhelmsen, P. Bjorntorp, and G. Tibblin, Br. Med. J. 288, 1401 (1984).

[30] Report of a WHO consultation, World Health Organ Tech Rep Ser, 2000; 894: i-xii, 1-253.

[31] National Institute of Health, http://www.nhlbi.nih.gov/ guidelines/obesity/ob_ddlns.pdf

[32] J. St-Pierre, I. Lemieux, M. C. Vohl, P. Perron, G. Tremblay, J. P. Després, and D. Gaudet, Am. J. Cardiol. 90, 15
(2002).

[33] A. H. Kissebah, Diabetes Res. Clin. Pract. 30, 25 (1996).

[34] J. M. Chan, E. B. Rimm, G. A. Colditz, M. J. Stamfer, and W. C. Willett, Diabetes Care. 17, 961 (1994).

[35] P. Arner, Ann. Med. 27, 435 (1995).

[36] E. Ferrannini, E. J. Barrett, S. Bevilacqua, and R. A. DeFronzo, J. Clin. Invest. 72, 1737 (1983).

[37] A. C. Perry, E. B. Applegate, M. L. Jackson, S. Deprima, R. B. Goldberg, R. Ross, L. Kempner, and B. B. Feldman, J. Appl. Physio. 89, 636 (2000).

[38] P. M. McKeigue, B. Shah, and M. G. Marmot, Lancet. 337, 382 (1991).

[39] Y. Kim, Y. Suh, and H. Choi, Obes. Res. 3, 445 (2004).

[40] G. Tornaghi, R. Raiteri, C. Pozzato, A. Rispoli, M. Bramani, M. Cipolat, and A. Craveri, Int. J. Obes. Relat. Metab. Disord. 18, 771 (1994).

[41] K. van der Kooy, R. Leenen, J. C. Seidell, P. Deurenberg, A. Droop, and C. J. Bakker, Am. J. Clin. Nutr. 57, 327 (1993).

[42] E. S. Kim, Y. S. Noh, K. S. Seo, S. B. Park, and H. R. Yoon, J. Biomed. Eng. Res. 31, 375 (2010).

[43] J. L. Clasey, C. Bouchard, C. D. Teates, J. E. Riblett, M. O. Thorner, M. L. Hartman, and A. Weltman, Obes. Re. 7, 256 (1999).

[44] J. D. Yeo and B. K. Jeon, JKCA. 6, 252 (2011).

[45] J. Machann, C. Thamer, B. Schnoedt, M. Haap, H. U. Haring, C. D. Claussen, M. Stumvoll, A. Fritsche, and F. Schick, J. Magn. Reson. Imaging. 21, 455 (2005).

[46] R. Ross, L. Leger, R. Guardo, J. De Guise, and B. G. Pike, J. Appl. Physiol. 70, 2164 (1991).

[47] P. Beddy, R. D. Rangarajan, M. Kataoka, P. Moyle, M. J. Graves, and E. Sala, Radiology 258, 583 (2011).

[48] H. J. Kim, S. E. Taksali, S. Dufour, D. Befroy, T. R. Goodman, K. F. Petersen, G. I. Shulman, S. Caprio, and R. T. Constable, Magn. Reson. Med. 59, 525 (2008).

[49] K. J. Ellis, B. Grund, F. Visnegarwala, L. Thackeray, C. G. Miller, and C. E. Chesson, Obesity. 15, 1441 (2007).

[50] J. R. Greenfield, K. Samaras, D. J. Chisholm, and L. V. Campbell, Obes. Res. 10, 260 (2002).

[51] M. Warren, P. J. Schreiner, and J. G. Terry, Am. J. Epidemiol. 163, 352 (2006).

[52] R. Ross, K. D. Shaw, Y. Martel, J. de Guise, and L. Avruch, Am. J. Clin. Nutr. 57, 470 (1993).

[53] R. Nakai, T. Azuma, T. Kishimoto, T. Hirata, O. Takizawa, S. H. Hyon, and S. Tsutsumi, J. Magnetic. Resonance Imaging 28, 520 (2010).

[54] X. H. Li, J. Zhu, X. M. Zhang, Y. F. Ji, T. W. Chen, X. H. Huang, L. Yang, and N. L. Zeng, J. Magn. Reson. Imaging 40, 58 (2014).

[55] T. Nakamura, K. Tokunaga, I. Shimomura, and M. Nishida, Atheroscl. 107, 239 (1994).

[56] A. Vermeulen, J. Clin. Endocrinol. Metab. 73, 221 (1991).

[57] M. Rebuffé-Scrive, L. Enk, N. Crona, P. Lönnroth, L. Abrahamsson, U. Smith, and P. Bjorntorp, J. Clin. Invest. 75, 1973 (1985). 